\title{
Efeitos de Culturas na Persistência de Herbicidas Auxínicos NO SOLO ${ }^{1}$
}

\author{
Effects of Cultures on the Persistence of Auxinic Herbicides in Soil
}

\author{
D’ANTONINO, L. ${ }^{2}$, SILVA, A.A. ${ }^{3}$, FERREIRA, L.R. ${ }^{3}$, CECON, P.R. ${ }^{4}$, QUIRINO, A.L.S. ${ }^{5}$ e \\ FREITAS, L.H.L. ${ }^{6}$
}

\begin{abstract}
RESUMO - Objetivou-se com este trabalho desenvolver técnicas para reduzir, no solo, a persistência de herbicidas utilizados em pastagens, visando implantar o sistema de integração lavoura-pecuária e culturas subsequentes. Para isso, foram realizados experimentos em condições de campo e casa de vegetação. No primeiro, avaliou-se a tolerância das culturas de milho e do sorgo aos herbicidas picloram + 2,4-D e 2,4-D, aplicados nas doses comerciais recomendadas pelo fabricante. No segundo experimento, realizado em casa de vegetação, avaliou-se o efeito residual desses herbicidas em diferentes condições de manejo da área. Para isso, foram avaliados nove tratamentos, sendo nas parcelas avaliados os tipos de cultivo (solo sem cultivo, cultivado com milho e cultivado com sorgo) e, nas subparcelas, as condições de manejo (plantas daninhas controladas por capinas manuais, controladas com 2,4-D e controladas com a mistura picloram + 2,4-D). O experimento em condições de campo foi realizado no município de Viçosa-MG, na época quente e úmida, em delineamento de blocos ao acaso com quatro repetições, em um Argissolo franco-argilo-arenoso de média fertilidade. Para realização do segundo experimento, utilizaram-se amostras de solo coletadas em todas as subparcelas do primeiro experimento aos 1, 42, 125 e 170 dias após a aplicação dos herbicidas (DAA). Neste trabalho, avaliou-se a persistência no solo dos herbicidas nos diferentes tratamentos, objetivando identificar a capacidade remediadora do solo pelas culturas de milho e sorgo, em comparação com o solo nu. Verificou-se que plantas de milho tiveram seu crescimento afetado pelos herbicidas, acumulando-se menores quantidades de matéria seca quando cultivadas em solos com residuos da mistura picloram +2 , 4-D, enquanto as de sorgo mostraram-se tolerantes. O efeito residual dos herbicidas no solo não foi influenciado pelas culturas de milho e sorgo, em relação ao solo sem cobertura vegetal. Não se observou intoxicação nas plantas indicadoras cultivadas em amostras de solo coletadas nas áreas tratadas com o 2,4-D na avaliação realizada a partir dos 42 DAA. Todavia, nas plantas cultivadas em amostras de solo coletadas nas parcelas que receberam a mistura picloram + 2,4-D, apenas a partir dos 150 DAA não se observaram mais sintomas de intoxicação das plantas indicadoras pelo picloram.
\end{abstract}

Palavras-chave: fitorremediação, picloram, 2,4-D, cultivos sucessivos.

\begin{abstract}
The objective of this work was to develop techniques to reduce, in soil, the persistence of herbicides used in pastures, to implement crop-breeding system integration and subsequent crops. Thus, experiments were performed under greenhouse and field conditions. The first one under field conditions (degraded pasture), aimed to evaluate the tolerance of maize and sorghum crops to herbicides (picloram $+2,4-D$ ) and 2,4-D, applied at commercial recommended rates. The second experiment conducted under greenhouse conditions aimed to evaluate the residual effect of these herbicides under different area management conditions. Nine treatments were assessed, with the main plots being composed by the crops (without soil cultivation, grown with corn and grown with sorghum) and by the subplots, management (weeds controlled by manual cultivation, with $2,4-D$, or with a mixture picloram $+2,4-D)$. The field experiment was installed in Viçosa-MG in hot
\end{abstract}

Recebido para publicação em 10.6.2008 e na forma revisada em 5.6.2009.

2 Engo-Agrō, D.Sc., do Dep. de Fitotecnia, Universidade Federal de Viçosa - DFT/UFV, 36570-000 Viçosa-MG, $<$ leonardo@ufv.br>; ${ }^{3}$ D.Sc., Professor Associado do Dep. de Fitotecnia-DFT/UFV; ${ }^{4}$ D. Sc., Professor Adjunto do Dep. de Informática - DEI/UFV; ${ }^{5}$ Engo-Agr ${ }^{0}$, Mestrando em Engenharia Agrícola UFV; ${ }^{6}$ Técnico Agrícola do Dep. de Fitotecnia - DFT/UFV.

Planta Daninha, Viçosa-MG, v. 27, n. 2, p. 371-378, 2009 
and humid season in a completely randomized block design, with four replications. The soil was a Red-Yellow Ultisol with median fertility. For the implementation of the second experiment under greenhouse conditions, soil samples collected in all subplots of the first experiment were used at 1, 42, 125 and 170 days after application (DAA) of herbicides. In this study, the persistence of the herbicides in the soil at each treatment was evaluated to identify soil remediation ability by maize and sorghum, compared with bare soil. It was found that corn plant growth was affected by the herbicides and accumulated lesser amount of dry mass when the corn plants were grown in soil with residues of picloram +2,4-D mixture, while sorghum was tolerant. The residual effect of the herbicides in the soil evaluated was not influenced by the crop species or soil management (corn, sorghum or bare soil). There was not any sign of poisoning in the indicative plants grown in soil samples collected in the areas treated with 2, 4-D in the evaluation conducted 42 DAA. However, plants grown in soil samples that received the mixture picloram $+2,4-D$, showed no intoxication symptoms only after 150 DAA.

Keywords: phytoremediation, picloram, 2,4-D, successive crops

\section{INTRODUÇÃO}

Na busca de um manejo racional da terra, surgiram nos últimos anos sistemas agrícolas envolvendo a integração entre lavoura e pecuária. Esses sistemas procuram maximizar o uso da terra e o rendimento das culturas (Kluthcousky \& Aidar, 2003). Todavia, um dos grandes problemas que dificultam a adoção dessa tecnologia para as diversas culturas refere-se ao efeito residual de herbicidas utilizados na formação e manutenção das pastagens. Para a formação de pastagens no sistema convencional, o solo é preparado com aração e gradagens e raramente se utilizam corretivos e fertilizantes, mesmo em solos ácidos de baixa fertilidade. Contudo, no controle das plantas daninhas normalmente são utilizados herbicidas persistentes. Esses herbicidas podem causar intoxicação em espécies sensiveis, como soja, feijão, algodão e outras dicotiledôneas, quando cultivadas em sequência (Silva et al., 2006). A persistência no solo responsável pela intoxicação de culturas sensíveis semeadas subsequentemente à pastagem (carryover) pode variar de alguns meses a mais de três anos, dependendo do produto, da dose utilizada, do solo e do clima (Bovey et al., 1982). Santos et al. (2006) verificaram resíduos em solo de textura argilo-arenosa até 360 dias após a aplicação de misturas comerciais de herbicidas que continham picloram na formulação. Além do carryover, existe ainda o problema ambiental ocasionado pela lixiviação dos herbicidas ou de seus metabólitos secundários no perfil do solo, podendo chegar a aquíferos subterrâneos (Dornelas de Souza et al., 2001).
O 2,4-D e a mistura picloram + 2,4-D, herbicidas registrados para pastagens no Brasil, são compostos extremamente ativos em dicotiledôneas, além de serem fracamente adsorvidos no solo. Particularmente, o picloram apresenta longa persistência no ambiente, com meia-vida de 20 a 300 dias (Silva et al., 2007), podendo ser encontrado no solo até três anos após sua aplicação (Deubert \& Corte-Real, 1986). O 2,4-D apresenta persistência curta a média nos solos e, em doses normais, a atividade residual não excede a quatro semanas em solos argilosos e clima quente (Silva et al., 2007).

A fitorremediação utiliza espécies vegetais capazes de remover ou degradar xenobióticos no solo (Pires et al., 2005a) e, consequentemente, permitir o cultivo subsequente de espécies sensíveis na área. Trabalhos realizados em países de clima temperado constataram a eficiência de plantas na remediação de herbicidas como atrazine (Anderson et al., 1994; Perkovich et al., 1996; Arthur et al., 2000), simazine (Wilson et al., 2000) e metolachlor (Anderson \& Coats, 1995; Rice et al., 1997). No Brasil, diversas pesquisas têm sido conduzidas mostrando a viabilidade de utilizar plantas na remediação dos herbicidas tebuthiuron (Pires et al., 2005a,b, 2006), trifloxysulfuron-sodium (Santos et al., 2004; Procópio et al., 2005a,b, 2006), além do 2,4-D + picloram (Ferreira et al., 2006). Para tebuthiuron e trifloxysulfuronsodium, as espécies de melhor desempenho foram Stizolobium aterrimum (mucuna-preta) e Cannavalia ensiformis (feijão-de-porco); no caso 
do 2,4-D + picloram, Brachiaria brizantha (marandu) e Penisetum glaucum (milheto) mostraram-se promissoras na remediação desse herbicida no solo.

Objetivou-se com este trabalho avaliar a tolerância de milho e sorgo aos herbicidas auxínicos 2,4-D e 2,4-D + picloram e avaliar o efeito dessas culturas e de plantas daninhas no efeito residual desses herbicidas no solo.

\section{MATERIAL E MÉTODOS}

Este trabalho constou de dois experimentos realizados em campo e casa de vegetação em Viçosa-MG (altitude: 648,74 m; latitude: 20 45'14"S; longitude: 42 52' 53" W; coordenadas UTM (m): 7.703.630 N e 720.570 E), em Argissolo franco-argilo-arenoso de baixa fertilidade, caracterizado fisico-quimicamente na Tabela 1.

No experimento de campo, sem irrigação, as parcelas $\left(480 \mathrm{~m}^{2}\right)$ foram constituídas por solo não cultivado, solo cultivado com milho (cultivar AG 2060) e solo cultivado com sorgo (cultivar BR 800), sendo a semeadura direta realizada em 6/11/2006. As subparcelas $\left(160 \mathrm{~m}^{2}\right)$ foram compostas pela mistura dos herbicidas picloram + 2,4-D $\left(256+960 \mathrm{~g} \mathrm{ha}^{-1}\right), 2,4-\mathrm{D}$ em aplicação isolada (960 $\mathrm{g} \mathrm{ha}^{-1}$ ) e uma testemunha sem aplicação de herbicidas, a qual foi capinada manualmente aos 30 e 90 dias após o plantio das culturas. Anteriormente ao plantio, foi realizada dessecação da área, com $5 \mathrm{~L} \mathrm{ha}^{-1}$ de glyphosate. A adubação constou de $400 \mathrm{~kg} \mathrm{ha}^{-1}$ da mistura comercial 08-28-16, na época da semeadura, sendo realizada cobertura manual com $50 \mathrm{~kg} \mathrm{ha}^{-1}$ de ureia, 35 dias após a emergência das plantas. A aplicação dos herbicidas foi feita em $7 / 11 / 2006$, utilizando-se de um pulverizador costal manual equipado com dois bicos XR 11002, espaçados de 0,5 m, com volume de calda de $67 \mathrm{~L} \mathrm{ha}^{-1}$. Em ambos os experimentos, o delineamento experimental adotado foi em blocos ao acaso, em esquema de parcela subdividida, com quatro repetições. O delineamento experimental utilizado na produção final de grãos de milho foi o de blocos ao acaso, com quatro repetições.

Com o objetivo de avaliar a tolerância das culturas aos herbicidas, foram coletadas plantas de milho aos 15, 30, 45, 60, 75 e 90 dias após a emergência (DAE) e de sorgo, aos 15, 30,45, 60, 75, 90, 105, 120 e $135 \mathrm{DAE}$, sendo deteminada a matéria seca dessas plantas. Para isso, todo o material colhido foi seco em estufa de circulação forçada de ar $\left(70 \pm 2{ }^{\circ} \mathrm{C}\right)$ até massa constante e pesado. Avaliou-se, ainda, a produtividade de grãos do milho por ocasião da colheita da cultura, realizada aos 125 dias após o plantio. Além das colheitas para avaliação da matéria seca das plantas de sorgo, aos 45 e 90 dias fez-se o corte de todas as plantas da parcela, a $25 \mathrm{~cm}$ de altura em relação ao solo, simulando-se o pastejo, sendo o material retirado da área experimental. Assim, os intervalos de avaliação das plantas de sorgo compreenderam três períodos de 45 dias de crescimento dessas plantas.

$\mathrm{O}$ segundo experimento foi realizado em casa de vegetação, utilizando-se como substrato amostras de solo coletadas em todas as subparcelas do experimento em campo, na

Tabela 1 - Composição química e textural do solo utilizado nos experimentos. Viçosa-MG, 2006/2007

\begin{tabular}{|c|c|c|c|c|c|c|c|c|c|c|}
\hline \multicolumn{11}{|c|}{ Análise granulométrica $\left(\mathrm{dag} \mathrm{kg}^{-1}\right)$} \\
\hline \multicolumn{2}{|c|}{ Argila } & \multicolumn{2}{|c|}{ Silte } & \multicolumn{2}{|c|}{ Areia fina } & \multicolumn{2}{|c|}{ Areia grossa } & \multicolumn{3}{|c|}{ Classificação textural } \\
\hline \multicolumn{2}{|c|}{25} & \multicolumn{2}{|c|}{16} & \multicolumn{2}{|c|}{22} & \multicolumn{2}{|c|}{37} & \multicolumn{3}{|c|}{ Franco Argilo Arenosa } \\
\hline \multicolumn{11}{|c|}{ Análise química } \\
\hline $\mathrm{pH}$ & $P$ & $\mathrm{~K}^{+}$ & $\mathrm{Al}^{3+}$ & $\mathrm{Ca}^{2+}$ & $\mathrm{Mg}^{2+}$ & $\mathrm{H}+\mathrm{Al}$ & CTCtotal & $\mathrm{V}$ & $\mathrm{m}$ & MO \\
\hline$\left(\mathrm{H}_{2} \mathrm{O}\right)$ & $\left(\mathrm{mg} \mathrm{dm}^{-3}\right)$ & \multicolumn{7}{|c|}{$\left(\mathrm{cmol}_{\mathrm{c}} \mathrm{dm}^{-3}\right)$} & $(\%)$ & $\left(\right.$ dag kg $\left.^{-1}\right)$ \\
\hline 5,9 & 5,2 & 81 & 0,0 & 2,8 & 1,4 & 2,64 & 4,41 & 63 & 0 & 2,55 \\
\hline
\end{tabular}

Análises realizadas no Laboratório de Análises de Solo Viçosa, segundo a metodologia da Empresa Brasileira de Pesquisa Agropecuária Embrapa (1997). 
profundidade de 0 a $20 \mathrm{~cm}$, em diferentes períodos após a aplicação dos herbicidas $(1,42$, 125 e 170 dias após a aplicação - DAA). Essas amostras de solo foram secas ao ar e peneiradas; posteriormente, foram preenchidos vasos sem perfuração de $0,5 \mathrm{dm}^{3}$ de capacidade com 350 g delas. Em seguida, umedeceu-se o solo dos vasos com água, realizou-se a pesagem deles e semeou-se o pepino (Cucumis sativus) como planta indicadora, conforme recomendado por Silva et al. (2006). Durante o período de cultivo da planta indicadora os vasos foram irrigados duas vezes por dia, sendo pesados diariamente para reposição de água, levandose em consideração o peso obtido após a saturação dos solos. Aos cinco dias após a emergência das plantas, cada vaso foi irrigado com $30 \mathrm{~mL}$ de solução com $5 \mathrm{~g} \mathrm{~L}^{-1}$ de adubo foliar Ouro Verde ${ }^{\circledR}$, contendo (dag kg-1): N $(15,0), \mathrm{P}_{2} \mathrm{O}_{5}$ $(15,0), \mathrm{K}_{2} \mathrm{O}(20,0), \mathrm{CaO}(3,0), \mathrm{S}(4,0), \mathrm{MgO}(0,8)$, $\mathrm{Cl}(0,4), \mathrm{Mn}(0,3), \mathrm{Fe}(0,06), \mathrm{B}(0,05)$ e $\mathrm{Zn}(0,04)$. Os tratamentos foram avaliados aos 21 dias após a emergência, de acordo com escala de notas de 0 a $100 \%$ de intoxicação (EWRC, 1964), em que 0\% correspondeu à ausência de intoxicação e $100 \%$ à morte da planta. Nessa escala, a nota é atribuída de acordo com os sintomas de intoxicação por planta em relação à testemunha sem herbicida.

Para interpretação dos resultados, os dados foram submetidos a análise de variância, testes de médias e análises de regressão, sendo o modelo escolhido de acordo com o fenômeno biológico, pelo coeficiente de determinação e significância do coeficiente de regressão, adotando-se o nivel de significância de 5\%. Independentemente de a interação datas de coleta versus capina ser ou não significativa, optou-se pelo seu desdobramento.

\section{RESULTADOS E DISCUSSÃO}

Quanto aos efeitos dos tratamentos sobre o acúmulo de matéria seca de plantas de milho e sorgo no tempo, observaram-se resultados semelhantes até os 75 dias. Todavia, na avaliação realizada aos 90 dias. verificou-se que a aplicação de picloram + 2,4-D inibiu em $13,6 \%$ o acúmulo de matéria seca do milho $(\mathrm{P}<0,05)$, em relação à testemunha (Figura 1 e Tabela 2). Esses resultados evidenciam sensibilidade do milho ao picloram, mesmo sendo esse herbicida seletivo para gramineas. No entanto, apesar de a mistura de picloram + 2,4-D ter afetado a produção de matéria seca das plantas de milho, esse tratamento não afetou a produção final de grãos, quando comparado ao cultivo em solo sem uso de herbicidas (Tabela 3).

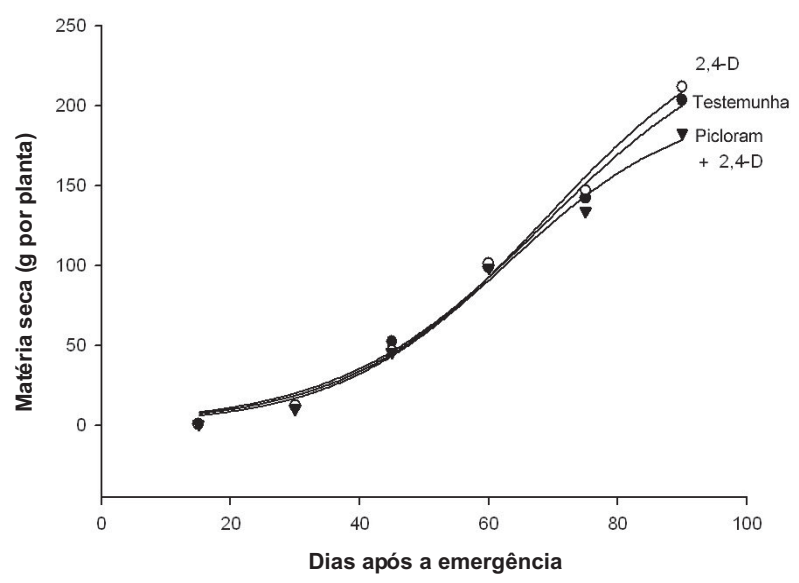

Figura 1 - Matéria seca de plantas de milho em função dos dias após a emergência, cultivadas em solo com aplicação de 2,4-D + picloram, 2,4-D isolado ou testemunha sem aplicação. Viçosa-MG, 2006/2007.

Tabela 2 - Efeito da aplicação de picloram + 2,4-D, 2,4-D isolado ou testemunha sem herbicidas no acúmulo de matéria seca de plantas de milho. Viçosa-MG, 2006/2007

\begin{tabular}{|l|c|c|c|c|c|c|c|c|}
\hline \multirow{2}{*}{ Tratamento } & \multicolumn{7}{|c|}{ Matéria seca $\left(\mathrm{g} \mathrm{m}^{-2}\right)(\mathrm{DAE})$} & \multirow{2}{*}{ Equação de regressão } \\
\cline { 2 - 8 } & 15 & 30 & 45 & 60 & 75 & 90 & $\mathrm{R}^{2}$ \\
\hline Testemunha & $1,08 \mathrm{a}$ & $12,04 \mathrm{a}$ & $52,60 \mathrm{a}$ & $99,27 \mathrm{a}$ & $142,37 \mathrm{a}$ & $203,75 \mathrm{a}$ & $\hat{\mathrm{Y}}=262,8289 /(1+\exp (-(\mathrm{x}-69,0862) / 15,2899))$ & 0,99 \\
\hline 2,4-D & $1,11 \mathrm{a}$ & $12,72 \mathrm{a}$ & $46,91 \mathrm{a}$ & $101,22 \mathrm{a}$ & $147,32 \mathrm{a}$ & $211,83 \mathrm{a}$ & $\hat{\mathrm{Y}}=252,0740 /(1+\exp (-(\mathrm{x}-68,5607) / 15,8523))$ & 0,99 \\
\hline Picloram + 2,4-D & $0,90 \mathrm{a}$ & $10,61 \mathrm{a}$ & $45,98 \mathrm{a}$ & $98,39 \mathrm{a}$ & $134,06 \mathrm{a}$ & $183,01 \mathrm{~b}$ & $\hat{\mathrm{Y}}=204,0995 /(1+\exp (-(\mathrm{x}-63,0006) / 13,8284))$ & 0,99 \\
\hline
\end{tabular}

Médias seguidas pela mesma letra, na coluna, não diferem entre si pelo teste de Tukey $(\mathrm{P}<0,05)$. 
Tabela 3 - Efeito da aplicação de picloram + 2,4-D, 2,4-D isolado e testemunha sem herbicidas sobre o rendimento de grãos de milho. Viçosa-MG, 2006/2007

\begin{tabular}{|l|c|}
\hline Tratamento & Produção $\left(\mathrm{kg} \mathrm{ha}^{-1}\right)$ \\
\hline Testemunha & 5878,83 \\
\hline $2,4-\mathrm{D}$ & 5902,58 \\
\hline Picloram + 2,4-D & 6230,25 \\
\hline
\end{tabular}

O crescimento das plantas de sorgo apresentou comportamento diferenciado em relação ao das plantas de milho (Figura 2 e Tabela 4). Até a data do primeiro corte (45 DAE), não houve diferença no acúmulo de matéria seca das plantas de sorgo (Tabela 5 e Figura 2). Entretanto, aos 75 e $90 \mathrm{DAE}$, coincidentemente com o segundo período de crescimento, ocorreram diferenças na matéria seca acumulada por essas plantas. Aos $75 \mathrm{DAE}$, houve redução de 4,3 e $2,8 \%$ no crescimento das plantas cultivadas em solo sem resíduos de herbicidas, em comparação àquelas cultivadas em solo com resíduos de 2,4-D e picloram + 2,4-D, respectivamente. Já aos $90 \mathrm{DAE}$, o acúmulo de matéria seca observado nas plantas de sorgo cultivadas em solo sem aplicação de herbicidas foi 12,0 e $17,3 \%$ inferior ao daquelas cultivadas em solo com resíduos de picloram $+2,4-\mathrm{D}$ e 2,4-D, respectivamente. Esses resultados podem ser atribuídos à menor infestação de plantas daninhas nas áreas tratadas com herbicidas, em relação às não-tratadas, o que resultou em interferência das plantas daninhas na cultura do sorgo. Isso ocorreu porque as capinas realizadas 30 e 90 dias depois não foram suficientes para eliminar as interferências das plantas daninhas. Essa elevada ocorrência de plantas daninhas pode estar relacionada à alta incidência de chuvas ocorridas no decorrer do ensaio (Figura 4), o que promoveu rápida reinfestação da área experimental. Além disso, foram constatadas algumas deficiências no processo de capina manual. A não-diferença significativa observada nos dados no período de crescimento compreendido dos 90 aos $135 \mathrm{DAE}$, referentes à brotação de plantas do segundo corte, pode ser atribuída à baixa concorrência das plantas daninhas com a cultura nesse período, pois estas se encontravam em final de ciclo (Tabela 5 e Figura 2).

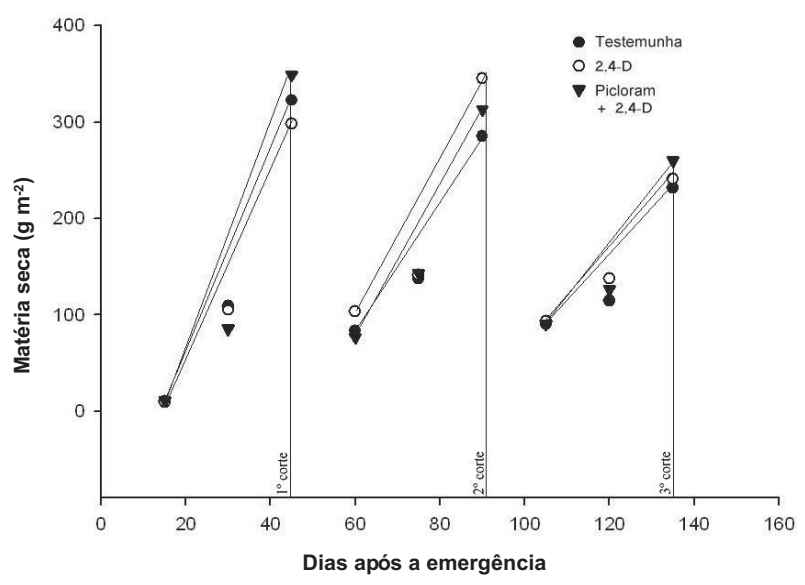

Figura 2 - Matéria seca em função dos dias após a emergência de plantas de sorgo cultivadas em solo com aplicação de 2,4-D + picloram, 2,4-D isolado ou testemunha sem aplicação. Viçosa-MG, 2006/2007.

Tabela 4 - Equações de regressão e coeficientes de determinação de acúmulo de matéria seca em plantas de sorgo cultivadas em solo com aplicação de 2,4-D + picloram, 2,4-D ou testemunha sem herbicidas. Viçosa-MG 2006/2007

\begin{tabular}{|l|c|c|c|}
\hline \multicolumn{1}{|c|}{ Tratamento } & 15 a 45 dias $\left(1^{\circ}\right.$ corte $)$ & 60 a 90 dias $\left(2^{\circ}\right.$ corte $)$ & 105 a 135 dias $\left(3^{\circ}\right.$ corte $)$ \\
\hline \multirow{2}{*}{ Testemunha } & $\hat{\mathrm{Y}}=156,13 \mathrm{D}-165,09$ & $\hat{\mathrm{Y}}=100,74 \mathrm{D}-32,958$ & $\hat{\mathrm{Y}}=70,776 \mathrm{D}+3,762$ \\
& $\mathrm{r}^{2}=0,96$ & $\mathrm{r}^{2}=0,93$ & $\mathrm{r}^{2}=0,87$ \\
\hline \multirow{2}{*}{$2,4-\mathrm{D}$} & $\hat{\mathrm{Y}}=144,36 \mathrm{D}-151,16$ & $\hat{\mathrm{Y}}=120,51 \mathrm{D}-44,521$ & $\hat{\mathrm{Y}}=73,605 \mathrm{D}+10,13$ \\
& $\mathrm{r}^{2}=0,96$ & $\mathrm{r}^{2}=0,86$ & $\mathrm{r}^{2}=0,95$ \\
\hline \multirow{2}{*}{ Picloram + 2,4-D } & $\hat{\mathrm{Y}}=168,65 \mathrm{D}-188,8$ & $\hat{\mathrm{Y}}=118,09 \mathrm{D}-58,677$ & $\hat{\mathrm{Y}}=84,514 \mathrm{D}-10,08$ \\
& $\mathrm{r}^{2}=0,90$ & $\mathrm{r}^{2}=0,94$ & $\mathrm{r}^{\mathrm{r}}=0,90$ \\
\hline
\end{tabular}


Quanto à persistência dos produtos no solo, observou-se comportamento diferenciado apenas para o solo contaminado com a mistura picloram + 2,4-D. Neste, verificou-se longa persistência de herbicidas, observando-se efeitos tóxicos do herbicida sobre a espécie indicadora cultivada em amostras coletadas até 150 dias após aplicação dos tratamentos (Tabela 6 e Figura 3). Santos et al. (2006) constataram resíduos de picloram em solos de pastagem aos 360 DAA. Embora, segundo Silva et al. (2007), o picloram tenha persistência no solo superior à observada, os resultados deste trabalho podem ser explicados pela elevada precipitação pluvial que ocorreu na área experimental durante a condução do trabalho (Figura 4), o que pode ter contribuído para a lixiviação do picloram para camadas mais profundas do solo. Segundo Rodrigues \& Almeida (2005), o picloram apresenta baixo Koc, o que o torna suscetível à lixiviação. Também Lavy et al. (1996) verificaram que o picloram apresenta alta persistência no ambiente, e Close at al. (1998) constataram fácil lixiviação do picloram. Estes autores detectaram a presença do picloram 600 dias após a sua aplicação, em profundidade de $1,3 \mathrm{~m}$, em trincheira feita nos solos em estudo. Assim, o ocorrido pode ser atribuído ao elevado volume de chuvas observado no período entre 50 e 120 DAA. Quanto à baixa persistência do 2,4-D no solo, não se

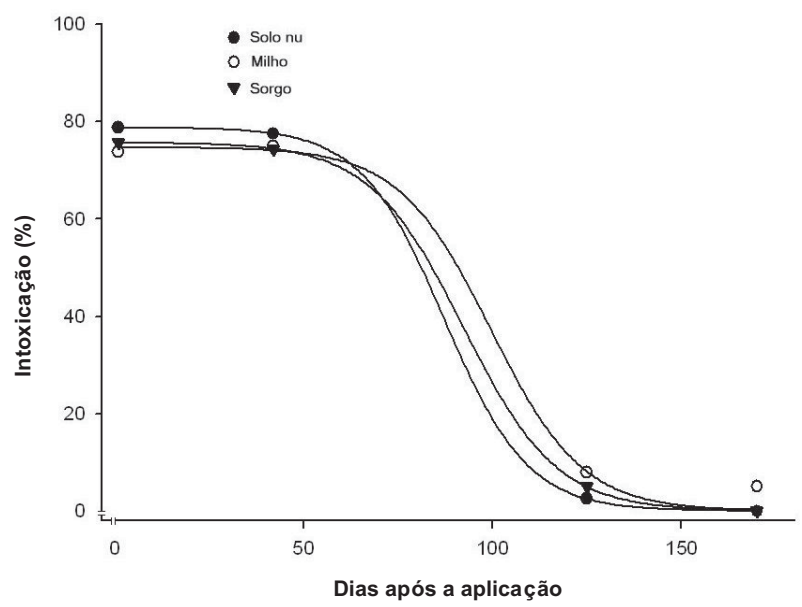

Figura 3 - Porcentagem de intoxicação em função dos dias após a aplicação, em plantas de pepino (Cucumis sativus) cultivadas em solos tratados com picloram $+2,4-\mathrm{D}$. ViçosaMG, 2006/2007

Tabela 5 - Valores médios do efeito da aplicação de picloram + 2,4-D, 2,4-D isolado ou testemunha sem herbicidas no acúmulo de matéria seca de plantas de sorgo. Viçosa-MG, 2006/2007

\begin{tabular}{|l|r|c|c|c|c|c|c|c|c|}
\hline \multirow{2}{*}{ Tratamento } & \multicolumn{10}{|c|}{ Matéria seca $\left(\mathrm{g} \mathrm{m}^{-2}\right)(\mathrm{DAE})$} \\
\cline { 2 - 11 } & 15 & 30 & 45 & 60 & 75 & 90 & 105 & 120 & 135 \\
\hline Testemunha & $10,24 \mathrm{a}$ & $108,74 \mathrm{a}$ & $322,49 \mathrm{a}$ & $83,53 \mathrm{a}$ & $137,03 \mathrm{~b}$ & $285,01 \mathrm{~b}$ & 90,102 & $114,18 \mathrm{a}$ & $231,65 \mathrm{a}$ \\
\hline 2,4-D & $9,58 \mathrm{a}$ & $104,80 \mathrm{a}$ & $298,30 \mathrm{a}$ & $103,72 \mathrm{a}$ & $143,12 \mathrm{a}$ & $344,73 \mathrm{a}$ & $93,517 \mathrm{a}$ & $137,78 \mathrm{a}$ & $240,73 \mathrm{a}$ \\
\hline Picloram + 2,4-D & $11,39 \mathrm{a}$ & $85,26 \mathrm{a}$ & $348,68 \mathrm{a}$ & $96,61 \mathrm{a}$ & $141,03 \mathrm{ab}$ & $322,79 \mathrm{a}$ & $90,65 \mathrm{a}$ & $126,49 \mathrm{a}$ & 259,68 \\
\hline \multicolumn{9}{|c|}{$\mathrm{CV}(\%)=20,07$} \\
\hline
\end{tabular}

Médias seguidas pela mesma letra, na coluna, não diferem entre si pelo teste de Tukey $(\mathrm{P}<0,05)$

Tabela 6 - Valores médios e equações de regressão ajustadas da intoxicação (\%) de plantas de pepino (Cucumis sativus) cultivadas em amostras de solos tratadas com picloram $+2,4-\mathrm{D}$, oriundas de plantios de milho, sorgo ou solo sem cultivo (nu). Viçosa-MG, $2006 / 2007$

\begin{tabular}{|c|c|c|c|c|c|c|}
\hline \multirow{2}{*}{ Tratamento } & \multicolumn{4}{|c|}{ Data de amostragem (DAE) } & \multirow{2}{*}{ Equações de Regressão } & \multirow{2}{*}{$\mathrm{R}^{2}$} \\
\hline & 1 & 42 & 125 & 170 & & \\
\hline Solo nu & 78,75 & 77,50 & 2,50 & 0,00 & $\hat{\mathrm{Y}}=78,7808 /(1+\mathrm{ex} \mathrm{p}(-(\mathrm{x}-87,2782) /-11,0342))$ & 0,99 \\
\hline Milho & 73,75 & 75,00 & 7,92 & 5,00 & $\hat{\mathrm{Y}}=75,6636 /(1+\exp (-(\mathrm{x}-92,2343) /-12,3649))$ & 0,96 \\
\hline Sorgo & 75,62 & 74,37 & 5,00 & 0,00 & $\hat{\mathrm{Y}}=74,7009 /(1+\operatorname{ex~} \mathrm{p}(-(\mathrm{x}-99,5105) /-12,1363))$ & 0,97 \\
\hline
\end{tabular}




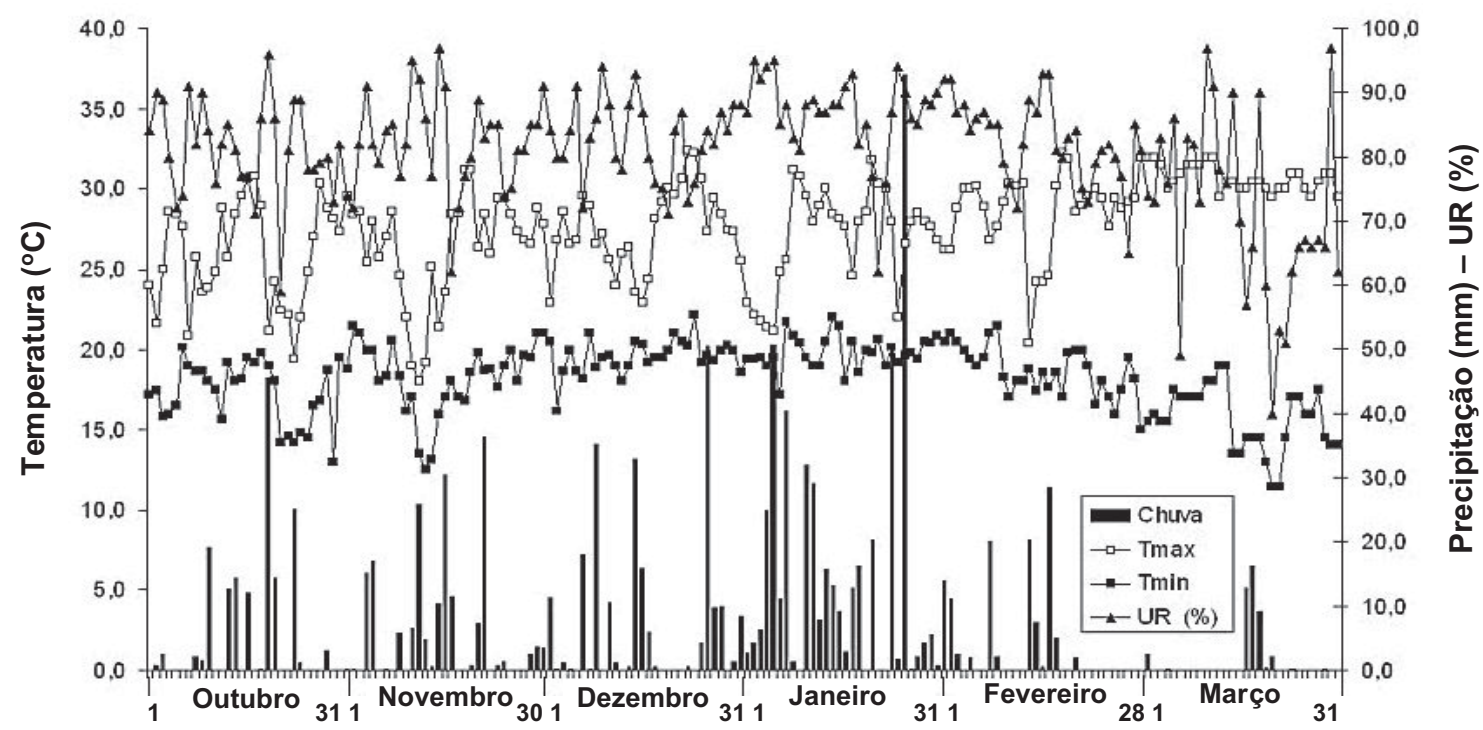

Figura 4 - Precipitação pluvial, temperaturas máximas e mínimas e umidade relativa do ar. Viçosa-MG, 2006/2007.

observando mais efeito sobre plantas bioindicadoras cultivadas em amostras de solo tratadas há 42 dias, confirma-se a afirmativa de Silva et al. (2007), os quais ratificam que a atividade residual do 2,4-D, em condições de clima tropical e boa distribuição de chuvas em solos argilosos, não excede a quatro semanas.

Com base nos resultados observados neste trabalho, concluiu-se que o crescimento de plantas de milho foi inferior em solos com resíduos do picloram, porém a produção final de grãos não foi influenciada. Contrariamente, o crescimento das plantas de sorgo não foi afetado pelos resíduos deste herbicida no solo. Quanto à persistência no solo, confirmaramse os resultados da literatura, evidenciando curto efeito residual no solo do 2,4-D e maior persistência do picloram. Foi evidenciado que as condições climáticas afetam de modo decisivo o comportamento do picloram no ambiente (Merkle et al., 1967; Bovey et al., 1975; Bovey \& Richardson, 1991). Todavia, não se observou efeito das culturas do milho e do sorgo sobre a persistência dos referidos herbicidas no solo.

\section{LITERATURA CITADA}

ANDERSON, T. A.; COATS, J. R. Screening rhizosphere soil samples for the ability to mineralize elevated concentrations of atrazine and metolachlor. J. Environ. Sci. Health, v. B30, n. 4, p. 473-484, 1995.
ANDERSON, T. A.; KRUGER, E. L.; COATS, J. R. Enhanced degradation of a mixture of three herbicides in the rhizosphere of a herbicide-tolerant plant. Chemosphere, v. 28, n. 8 , p. $1551-1557,1994$.

ARTHUR, E. L. et al. Degradation of an atrazine and metolachlor herbicide mixture in pesticide-contaminated soils from two agrochemical dealerships in Iowa. Water, Air, Soil Pollut., v. 119, n. 1, p. 75-90, 2000

BOVEY, R. W.; MEYER, R. E.; HEIN JR., H. Soil persistence of tebuthiuron in the Claypan Resource Area of Texas. Weed Sci., v. 30, n. 2, p. 140-144, 1982.

BOVEY, R. W. et al. Occurrence of 2,4,5-T and picloram in subsurface waterin the blacklands of Texas. J. Environ. Quality, v. 4, n. 1, p. 103-106, 1975.

BOVEY, R. W.; RICHARDSON, C. W. Dissipation of clopyralid and picloram in soil and seep flow in the blacklands of Texas. J. Environ. Quality, v. 20, n. 3, p. 528-531, 1991.

CLOSE, M. E. et al. Leaching of picloram, atrazine and simazine through two New Zealand soils. Geoderma, v. 84, n. 1, p. $46-63,1998$

DEUBERT, K. H.; CORTE-REAL, I. Soil residues of picloram and triclopyr after selective foliar application on utility rights-of-way. J. Arboric., v. 12, n. 11, p. 269-272, 1986.

DORNELAS DE SOUZA, M. et al. Adsorção e lixiviação de tebuthiuron em três tipos de solo. R. Bras. Ci. Solo, v. 25, n. 4, p. 1053-1061, 2001 
EMPRESA BRASILEIRA DE PESQUISA

AGROPECUÁRIA - EMBRAPA. Centro Nacional de Pesquisa de Solos. Manual de métodos de análise de solo. 2.ed. Rio de Janeiro: 1997. 212 p.

EUROPEAN WEED RESEARCH COUNCIL - EWRC Report of $3 \mathrm{rd}$ and $4 \mathrm{rd}$ meetings of EWRC. Cittee of methods in weed research. Weed Res., v. 4, n. 1, p. 88, 1964

FERREIRA, L. R. et al. Seleção de espécies com potencial de remediação de solos contaminados com os herbicidas triclopyr e 2,4-D + picloram. In: CONGRESSO BRASILEIRO DA CIÊNCIA DAS PLANTAS DANINHAS, 25., 2006, Brasília. Anais... Brasília: 2006. p. 228

KLUTHCOUSKI, J.; ADAR, H. Uso da integração lavoura pecuária na recuperação de pastagens degradadas. In: KLUTHCOUSKI, J. et al. Integração lavoura pecuária. Santo Antônio de Goiás: Embrapa Arroz e Feijão, 2003. p. $185-223$

LAVY, T. L. et al. Long-term in situ leaching and degradation of six herbicides aged in subsoils. J. Environ. Quality, v. 25, n. 6, p. 1268-1279, 1996

MERKLE, M. G;; BOVEY, R. W.; DAVIS, F. S. Factors affecting the persistance of picloram in soil. Agron. J., v. 59, n. 4, p. 413-415, 1967.

PERKOVICH, B. S. et al. Enhanced mineralization of $\left[{ }^{14} \mathrm{C}\right]$ atrazine in Kochia scoparia rhizosferic soil from a pesticidecontaminated site. Pestic. Sci., v. 46, n. 4, p. 391-396, 1996.

PIRES, F. R. et al. Adubos verdes na fitorremediação de solos contaminados com o herbicida tebuthiuron. Caatinga, v. 19, n. 1, p. 92-97, 2006

PIRES, F. R. et al. Inferências sobre a atividade rizosférica de espécies com potencial para fitorremediação do herbicida tebuthiuron. R. Bras. Ci. Solo, v. 29, n. 4, p. 627-634, 2005a.

PIRES, F. R. et al. Fitorremediação de solos contaminados com tebuthiuron utilizando-se espécies cultivadas para adubação verde. Planta Daninha, v. 23, n. 4, p. 711-717, $2005 b$
PROCÓPIO, S. O. et al. Fitorremediação de solo contaminado com trifloxysulfuron sodium por diferentes densidades populacionais de feijão-de-porco (Canavalia ensiformis (L). DC.). Ci. Agrotec., v. 30, n. 3, p. 444-449, 2006.

PROCÓPIO, S. O. et al. Fitorremediação de solo contaminado com trifloxysulfuron sodium por mucuna-preta (Stizolobium aterrimum). Planta Daninha, v. 23, n. 4, p. 719-724, 2005a.

PROCÓPIO, S. O. et al. Potencial de espécies vegetais para a remediação do herbicida trifloxysulfuron-sodium. Planta Daninha, v. 23, n. 1, p. 9-16, 2005b.

RICE, P. J.; ANDERSON, T. A.; COATS, J. R. Phytoremediation of herbicide-contaminated surface water with aquatic plants. In: Phytoremediation of soil and water contaminants. Washington, DC: American Chemical Society, 1997. p. 133-151.

RODRIGUES, B. N.; ALMEIDA, F. S. Guia de herbicidas. 5.ed. Londrina: IAPAR, 2005. 591 p.

SANTOS, J. B. et al. Fitorremediação do herbicida trifloxysulfuron sodium. Planta Daninha, v. 22, n. 2, p. 223-330, 2004.

SANTOS, M. V. et al. Eficácia e persistência no solo de herbicidas utilizados em pastagem. Planta Daninha, v. 24, n. 2, p. 391-398, 2006.

SILVA, L. L. et al. Seleção de espéciesd sensíveis aos herbicidas triclopyr e 2,4-D + picloram. In: CONGRESSO BRASILEIRO DA CIENCIA DAS PLANTAS DANINHAS, 25., 2006, Brasília. Anais... Brasília, DF: 2006. p. 229.

SILVA, A. A. et al. Herbicidas: classificação e mecanismo de ação. In: SLLVA, A. A.; SILVA, J. F. (Eds.) Tópicos em manejo de plantas daninhas. Viçosa, $\mathrm{MG}$ : Universidade Federal de Viçosa, 2007. p. 83-148.

WILSON, P. C.; WHITWELL, T.; KLAINE, S. J. Phytotoxicity, uptake, and distribution of ${ }^{14} \mathrm{C}$-simazine in Acorus gramenius and Pontederia cordata. Weed Sci., v. 48, n. 6, p. 701-709, 2000. 